NASA/TM-2013-216553

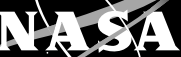

Nuclear Thermal Rocket Simulation in NPSS

Michael L. Belair, Charles J. Sarmiento, and Thomas M. Lavelle

Glenn Research Center, Cleveland, Ohio 


\section{NASA STI Program . . . in Profile}

Since its founding, NASA has been dedicated to the advancement of aeronautics and space science. The NASA Scientific and Technical Information (STI) program plays a key part in helping NASA maintain this important role.

The NASA STI Program operates under the auspices of the Agency Chief Information Officer. It collects, organizes, provides for archiving, and disseminates NASA's STI. The NASA STI program provides access to the NASA Aeronautics and Space Database and its public interface, the NASA Technical Reports Server, thus providing one of the largest collections of aeronautical and space science STI in the world. Results are published in both non-NASA channels and by NASA in the NASA STI Report Series, which includes the following report types:

- TECHNICAL PUBLICATION. Reports of completed research or a major significant phase of research that present the results of NASA programs and include extensive data or theoretical analysis. Includes compilations of significant scientific and technical data and information deemed to be of continuing reference value. NASA counterpart of peer-reviewed formal professional papers but has less stringent limitations on manuscript length and extent of graphic presentations.

- TECHNICAL MEMORANDUM. Scientific and technical findings that are preliminary or of specialized interest, e.g., quick release reports, working papers, and bibliographies that contain minimal annotation. Does not contain extensive analysis.

- CONTRACTOR REPORT. Scientific and technical findings by NASA-sponsored contractors and grantees.
- CONFERENCE PUBLICATION. Collected papers from scientific and technical conferences, symposia, seminars, or other meetings sponsored or cosponsored by NASA.

- SPECIAL PUBLICATION. Scientific, technical, or historical information from NASA programs, projects, and missions, often concerned with subjects having substantial public interest.

- TECHNICAL TRANSLATION. Englishlanguage translations of foreign scientific and technical material pertinent to NASA's mission.

Specialized services also include creating custom thesauri, building customized databases, organizing and publishing research results.

For more information about the NASA STI program, see the following:

- Access the NASA STI program home page at http://www.sti.nasa.gov

- E-mail your question to help@sti.nasa.gov

- Fax your question to the NASA STI Information Desk at 443-757-5803

- Phone the NASA STI Information Desk at 443-757-5802

- Write to: STI Information Desk NASA Center for AeroSpace Information 7115 Standard Drive Hanover, MD 21076-1320 
NASA/TM-2013-216553

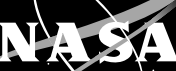

Nuclear Thermal Rocket Simulation in NPSS

Michael L. Belair, Charles J. Sarmiento, and Thomas M. Lavelle

Glenn Research Center, Cleveland, Ohio

Prepared for the

49th Joint Propulsion Conference and Exhibit

cosponsored by AIAA, ASME, SAE, and ASEE

San Jose, California, July 14-17, 2013

National Aeronautics and

Space Administration

Glenn Research Center

Cleveland, Ohio 44135

July 2013 


\section{Acknowledgments}

The authors would like to thank Stan Borowski, Jim Fittje, and Bruce Schnitlzer for their support and technical input on the project. This work was performed with funding from the Nuclear Cryogenic Propulsion Stage (NCPS) project established as part of the Advanced Exploration Systems Program.

Trade names and trademarks are used in this report for identification only. Their usage does not constitute an official endorsement, either expressed or implied, by the National Aeronautics and Space Administration.

Level of Review: This material has been technically reviewed by technical management.

Available from

NASA Center for Aerospace Information 7115 Standard Drive

Hanover, MD 21076-1320
National Technical Information Service 5301 Shawnee Road Alexandria, VA 22312

Available electronically at http://www.sti.nasa.gov 


\title{
Nuclear Thermal Rocket Simulation in NPSS
}

\author{
Michael L. Belair, Charles J. Sarmiento, and Thomas M. Lavelle \\ National Aeronautics and Space Administration \\ Glenn Research Center \\ Cleveland, Ohio 44135
}

\begin{abstract}
Four nuclear thermal rocket (NTR) models have been created in the Numerical Propulsion System Simulation (NPSS) framework. The models are divided into two categories. One set is based upon the ZrC-graphite composite fuel element and tie tube-style reactor developed during the Nuclear Engine for Rocket Vehicle Application (NERVA) project in the late 1960s and early 1970s. The other reactor set is based upon a W-UO2 ceramicmetallic (CERMET) fuel element. Within each category, a small and a large thrust engine are modeled. The small engine models utilize RL-10 turbomachinery performance maps and have a thrust of approximately $33.4 \mathrm{kN}(7,500 \mathrm{lbf})$. The large engine models utilize scaled RL-60 turbomachinery performance maps and have a thrust of approximately 111.2 $\mathrm{kN}$ (25,000 lbf). Power deposition profiles for each reactor were obtained from a detailed Monte Carlo N-Particle (MCNP5) model of the reactor cores. Performance factors such as thermodynamic state points, thrust, specific impulse, reactor power level, and maximum fuel temperature are analyzed for each engine design.
\end{abstract}

\section{Nomenclature}

$\begin{array}{ll}\text { AR } & \text { Area Ratio } \\ \text { CERMET } & \text { Ceramic-Metallic fuel element } \\ \text { DRA } & \text { Design Reference Architecture } \\ \mathrm{g} & \text { Acceleration of gravity at sea level } \\ \gamma & \text { Ratio of specific heats } \\ \text { GRC } & \text { Glenn Research Center } \\ \mathrm{I}_{\mathrm{sp}} & \text { Specific Impulse } \\ \mathrm{kN} & \text { kilownewtons force } \\ \mathrm{lb}_{\mathrm{f}} & \text { pounds force } \\ \mathrm{MCNP} & \text { Monte Carlo N-Particle transport code } \\ \mathrm{MW} & \text { Megawatts } \\ M W & \text { Molecular Weight } \\ \mathrm{NCPS} & \text { Nuclear Cryogenic Propulsion Stage } \\ \mathrm{NERVA} & \text { Nuclear Engine for Rocket Vehicle Application } \\ \mathrm{NESS} & \text { Nuclear Engine System Simulation } \\ \mathrm{NPSS} & \text { Numerical Propulsion System Simulation code } \\ \mathrm{NTP} & \text { Nuclear Thermal Propulsion } \\ \mathrm{NTR} & \text { Nuclear Thermal Rocket } \\ \mathrm{P}_{\mathrm{e}} & \text { Exhaust Pressure } \\ \mathrm{P}_{\mathrm{i}} & \text { Inlet Pressure } \\ \mathrm{R} & \text { Universal Gas Constant } \\ \mathrm{SNRE} & \text { Small Nuclear Rocket Engine } \\ \mathrm{T} & \text { Temperature }\end{array}$




\section{Introduction}

NUClEar thermal propulsion (NTP) is identified as the preferred propulsion technology for manned misNions to Mars in NASA's Design Reference Architecture (DRA) 5.0. ${ }^{1}$ NTP is the preferred propulsion technology because it has heritage and higher performance than current propulsion systems available at the thrust levels necessary for manned missions. The Nuclear Cryogenic Propulsion Stage (NCPS) project is engaged in conceptual design of a small $33.4 \mathrm{kN}\left(7,500 \mathrm{lb}_{\mathrm{f}}\right)$ and a full-size/large $111.2 \mathrm{kN}\left(25,000 \mathrm{lb}_{\mathrm{f}}\right)$ class nuclear rocket. The small engine could be used for a flight demonstration mission as well as possible robotic probe missions. The large nuclear engine is intended to be used in a clustered configuration for human exploration missions. ${ }^{2}$

In support of the NCPS project, the NASA Glenn Research Center (GRC) has been working to model four nuclear thermal rockets in the Numerical Propulsion System Simulation (NPSS) framework. The main intent of this work is to analyze the overall system performance and operation of a nuclear thermal rocket. Existing turbomachinery design were simulated to mitigate the eventual cost of a turbomachinery development effort. The four engine models are broken into two categories based on the fuel element type. One fuel element is based on the design from the Nuclear Engine for Rocket Vehicle Application (NERVA) project and another is a ceramic-metallic (CERMET) fuel element design. The small engine models utilize a RL-10 type hydrogen turbopump and the larger engine models attempt to utilize a dual RL-60 type hydrogen turbopump configuration.

The Rover program which included the Nuclear Engine for Rocket Vehicle Application (NERVA) project demonstrated the concept of a nuclear rocket was feasible. The Rover/NERVA program was quite successful and developed twenty rocket reactors that were built and ground tested. The reactor design that resulted from the NERVA project is the basis for one of the reactor sets analyzed. ${ }^{3}$

\section{A. Advantages of Nuclear Propulsion}

The overall concept of a nuclear rocket is simple. In most conventional rocket systems, an extremely energetic and hot gas is produced and that energy is converted into kinetic energy by expanding the gas through a nozzle. In chemical propulsion systems, the energy is derived from the energy stored in chemical bonds. In a nuclear rocket, the energy is supplied by heating the hydrogen in a nuclear reactor core. The most common attribute evaluated to determine the performance of a rocket system is the specific impulse, $\mathrm{I}_{\mathrm{sp}}$. For the acceleration of gases in a nozzle, the specific impulse is a function of the absolute temperature and the molecular weight as given in Equation 1.

$$
I_{s p}=\frac{1}{g} \sqrt{\frac{2 \gamma}{\gamma-1} \frac{R T}{M W}\left(1-\left(\frac{P_{e}}{P_{i}}\right)^{\frac{\gamma-1}{\gamma}}\right)}
$$

The advantage of the nuclear rocket is that you are no longer dependent upon chemical reactions to obtain the high temperatures, so the molecular weight can be minimized and specific impulse can be maximized. Currently the highest performance propellant combination commonly used for chemical systems is hydrogen and oxygen. At a mixture ratio of 5.85:1, the combustion temperature is approximately $3420 \mathrm{~K}$, the average molecular weight is $13.8 \mathrm{~g} / \mathrm{mol}$, and the maximum theoretical specific impulse is near 480 seconds. In a nuclear rocket, the propellant is typically $\mathrm{H}_{2}$ with a molecular weight of $2.016 \mathrm{~g} / \mathrm{mol}$ and is heated to temperatures near $2700 \mathrm{~K}$. Based on the equation for specific impulse, the nuclear rocket has twice the expected specific impulse, approximately 900 seconds, as hydrogen and oxygen chemical propulsion.

The other advantage of nuclear systems is that technology advances could potentially increase performance. In a chemical system, you are ultimately limited by the energy available from the chemical reaction; however, in a nuclear rocket, the temperature of the propellant is only limited by the temperature limits of the reactor. Advanced reactor fuel design may be capable of increasing the propellant temperature significantly.

\section{B. Numerical Propulsion System Simulation (NPSS) Framework}

The Numerical Propulsion System Simulation (NPSS) software is a propulsion system simulation tool developed by NASA GRC and its industry and Government partners. ${ }^{4}$ NPSS is used in the aerospace industry to simulate aircraft engines and their components in a timely and cost-effective manner. NPSS has also 
been expanded to spacecraft applications due to its flexible nature. It allows developers to create their own custom elements that can be used in system simulations. For the NCPS modeling project, custom reactor and tie tube elements were developed to interface in the NPSS framework. The theory behind the reactor and tie tube thermodynamics and fluid mechanics is summarized elsewhere. ${ }^{5,6}$

\section{Turbomachinery Modeling}

\section{A. RL-10 Hydrogen Pump and Turbine}

The small class of engines utilizes the RL-10 hydrogen pump and turbine to power the engine. All RL-10 variants operate based on an expander cycle where the liquid hydrogen is heated in the regenerative nozzle and chamber and used to drive the turbine. The same type of cycle can be run for a nuclear rocket where the heat is obtained from the nozzle cooling section and the tie tubes. As of 2012, there are two variants of the RL-10 in use. $^{7}$ The two engines are summarized in Table 1.

Table 1. RL-10 Variants ${ }^{7}$

\begin{tabular}{lcc} 
& RL-10A4-2 & RL-10B-2 \\
\hline Propellants & LOX/LH2 & LOX/LH2 \\
Thrust (kN) & 99.2 & 110.1 \\
Chamber Pressure (MPa) & 4.21 & 4.41 \\
Mixture Ratio & $5.5: 1$ & $5.85: 1$ \\
Specific Impulse (seconds) & 451 & 464 \\
Area Ratio & $84: 1$ & $285: 1$ \\
Hydrogen Mass Flow Rate ${ }^{*}(\mathrm{~kg} / \mathrm{sec})$ & 3.45 & 3.54 \\
${ }^{*}$ Calculated based on thrust, specific impulse and mixture ratio.
\end{tabular}

The decision to simulate RL-10 turbomachinery was made because the hydrogen flow rate for the small nuclear rocket engine is very similar to the hydrogen flow rate of the RL-10. The expected flow rate needed for the small engine class is approximately $3.81 \mathrm{~kg} / \mathrm{sec}$ based on a thrust of $33.4 \mathrm{kN}$ and a specific impulse of 900 seconds. This flow rate represents an increase less than ten percent from the RL-10B-2 design.

\section{B. RL-60 Hydrogen Pump and Turbine}

The large class of nuclear engines, $111.2 \mathrm{kN}$ thrust, utilizes the turbomachinery from the RL-60 design to pump the liquid hydrogen through the reactor core. The RL-60 is an upgraded design from the RL-10. The RL-60 was designed to have a thrust of $266.9 \mathrm{kN}$ and a specific impulse of 465 seconds. The mixture ratio of the RL-60 was intended to be operated at a range of 5.0 to $6.0: 1$. The hydrogen flow rate through the engine is calculated to be $8.35-9.75 \mathrm{~kg} / \mathrm{sec}$. This flow rate is smaller than the expected flow rate of the large nuclear engines. The large nuclear engines are expected to have a flow rate of approximately $12.7 \mathrm{~kg} / \mathrm{sec}$ based on a thrust of $111.2 \mathrm{kN}$ and a specific impulse near 900 seconds.

Since there is approximately a 30-40 percent greater mass flow rate than the design level of the RL-60, it was decided to use a dual turbopump configuration. In this configuration, two RL-60 turbopump assemblies will operate in parallel at approximately 70 percent capacity in order to provide the necessary mass flow rate. In the event of a failure of one turbopump assembly, the engine could be operated at a lower power and thrust level if desirable.

\section{Fuel Element Descriptions}

\section{A. NERVA}

The NERVA derived engines utilize the (U,Zr)C-graphite hexagonal fuel element with structural support tie tubes that was the baseline design for the Small Nuclear Rocket Engine (SNRE). ${ }^{8}$ The fuel element has a flat to flat measurement of $1.905 \mathrm{~cm}$ and is $88.9 \mathrm{~cm}$ long for the small engine and $132.1 \mathrm{~cm}$ long for the large engine. Each fuel element contains 19 coolant passages with $0.257 \mathrm{~cm}$ diameter holes for the hydrogen 
coolant. The outer surface of the fuel element and the interior of the coolant channels are coated with a protective layer of $\mathrm{ZrC}$. The outer surface is coated to a thickness of 50 micrometers, and the coolant channels have a tapered coating varying from 50 micrometers at the inlet to 150 micrometers at the exit. More information on the NERVA derived fuel elements can be found in the references written by Schnitlzer and Fittje. ${ }^{9,10}$ Figure 1 below shows the details for the fuel element and tie tube geometry. ${ }^{10}$

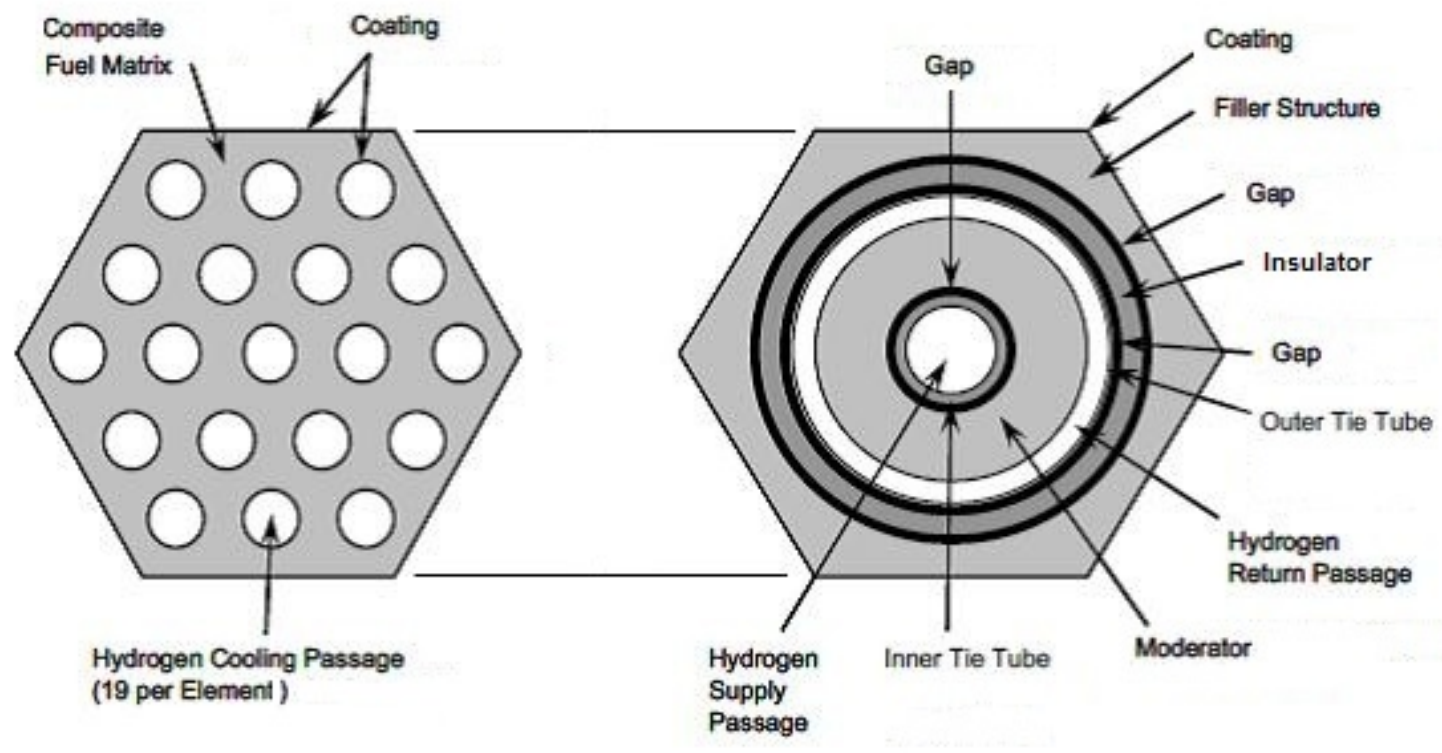

a) Typical NERVA Derived Fuel Element

b) Typical NERVA Derived Tie Tube

Figure 1. NERVA Derived Fuel Element and Tie Tube

\section{B. ANL-200 CERMET}

The CERMET engines utilize the fuel element known as ANL-200. The fuel element is composed of $\mathrm{Gd}_{2} \mathrm{O}_{3}$ stabilized $\mathrm{UO}_{2}$ particles in a tungsten matrix. The fuel element has a flat to flat measurement of $2.774 \mathrm{~cm}$ and is $60.96 \mathrm{~cm}$ long for the small engine and $86.36 \mathrm{~cm}$ long for the large engine. Each fuel element contains 61 coolant passages with $0.170 \mathrm{~cm}$ diameter holes for the hydrogen coolant. The outer surface of the fuel element and the interior of the coolant channels are coated with a $0.01778 \mathrm{~cm}$ protective layer of $\mathrm{W}-25 \mathrm{wt} \%$ Re. Figure 2 below shows the general arrangement of the fuel element in a reactor core. ${ }^{11}$

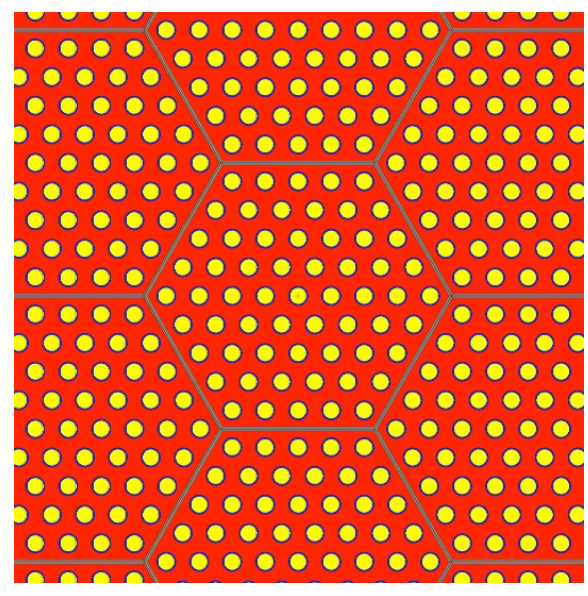

Figure 2. ANL-200 Fuel Element 


\section{Small NERVA Derived Engine}

\section{A. Engine Configuration}

Since thrust is proportional to reactor power, the small engine is modeled in order to have enough thermal power to produce approximately $33.4 \mathrm{kN}$ of thrust. All of the engines tested during the NERVA project were designed for much higher thrust levels; Peewee was the smallest at $25 \mathrm{klb}_{\mathrm{f}}{ }^{3}$ In order to maintain criticality in the engine at such low thrust levels, a slightly different engine configuration had to be devised where the number of tie tubes was increased to a ratio near 1:1. The tie tubes improve criticality of the engine because they contain a zirconium hydride moderator. Figure 3 shows a detailed view of the general pattern concept. ${ }^{9}$

The engine configuration has a total of 260 fuel elements and 251 tie tube elements. The reactor thermal power output is set at approximately $162 \mathrm{MW}$. The reactor core is surrounded by a $14.7 \mathrm{~cm}$ thick radial reflector and control drums. The engine core is estimated to weigh $1432 \mathrm{~kg}$, containing approximately 27.5 $\mathrm{kg}$ of ${ }^{235} \mathrm{U}$. Figure 4 is an illustration of the entire core configuration. ${ }^{9}$

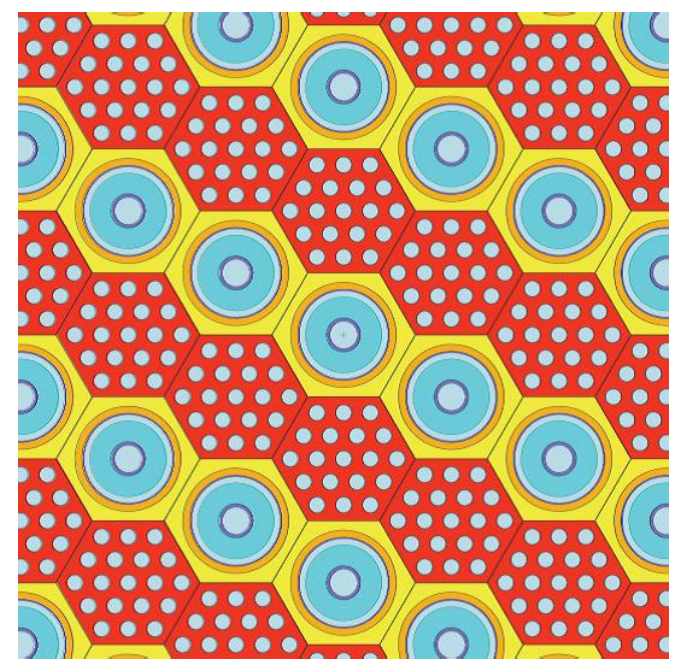

Figure 3. Dense (1:1) Fuel Element and Tie Tube Configuration

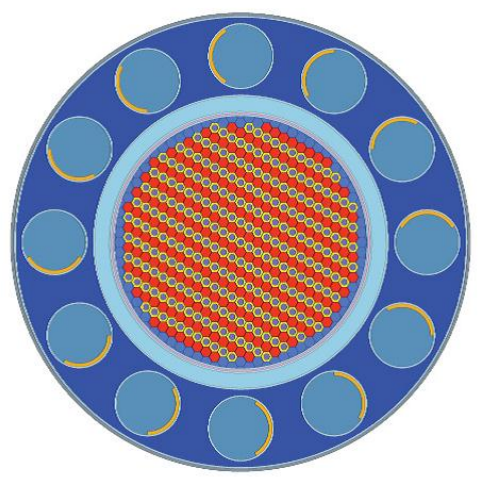

Figure 4. Small NERVA Core Configuration

A general description of the reactor and power distribution through the system is shown in Table 2 . 
Table 2. Small NERVA Derived Engine Summary

\begin{tabular}{lrc} 
Description & Value & Units \\
\hline Number of Fuel Elements & 260 & $\mathrm{NA}$ \\
Number of Tie Tubes & 251 & $\mathrm{NA}$ \\
Avg. Power Deposited Fuel Element & 0.586579 & $\mathrm{MW}$ \\
Reactor Total Power & 161.6 & $\mathrm{MW}$ \\
Fuel Element Hydrogen Heating & 140.7 & $\mathrm{MW}$ \\
Tie Tube Hydrogen Heating & 16.6 & $\mathrm{MW}$ \\
$\quad$ Conduction from Fuel Elements & 11.78 & $\mathrm{MW}$ \\
$\quad$ Nuclear Deposited & 4.84 & $\mathrm{MW}$ \\
Control Drum Hydrogen Heating & 3.45 & $\mathrm{MW}$
\end{tabular}

\section{B. Engine Flow Path}

One of the main design constraints of a nuclear rocket system is obtaining enough thermal energy to run the turbomachinery. For the NERVA derived engines, this is typically not an issue because the pressure drop through the engine is relatively low and there is plenty of available thermal energy from the tie tubes. In fact, there is significantly more thermal energy available than necessary to run the turbomachinery. In order to keep the turbine inlet temperature closer to the heritage RL-10 temperatures, an innovative flow path had to be considered to lower this temperature as much as possible.

First, the liquid hydrogen leaves the tank and passes through the fuel inlet valve. The hydrogen is then compressed through a two stage pump. Then the flow is split into two parallel paths. Part of the flow is directed to the tie tubes which provide structural support for the reactor as well as criticality. The remaining flow enters the nozzle and chamber regenerative cooling section. After the flow leaves the regenerative cooling section, it is directed up along the reactor to cool the control drums and radial reflectors. Once the flow exits the control drum/ radial reflector, it is recombined with a small fraction of the flow from the tie tubes. This combination is sent to the turbine. Some of the flow is allowed to bypass the turbine in order to control the flow rate of hydrogen through the pumps. Once the flow from the turbine, turbine bypass valve, and remaining tie tube flow recombine, it is directed to the reactor inlet. The gas that enters the reactor is then superheated to extremely high temperatures before it is exhausted through a nozzle. An illustration of the flow path can be seen in the model results for this engine, shown in Figure 5.

\section{Model Results}

The model was run to obtain a chamber pressure of $4.14 \mathrm{MPa}$ (600 psia) and a peak fuel temperature of 2860 $\mathrm{K}(5148 \mathrm{R})$. This specific state was chosen due to turbomachinery pump discharge pressure limitations and fuel element temperature limitations. It should be noted that the pressure drop through the regenerative cooling sections are estimated using resistance values that scale the pressure drop with the mass flow rate of the engine. 


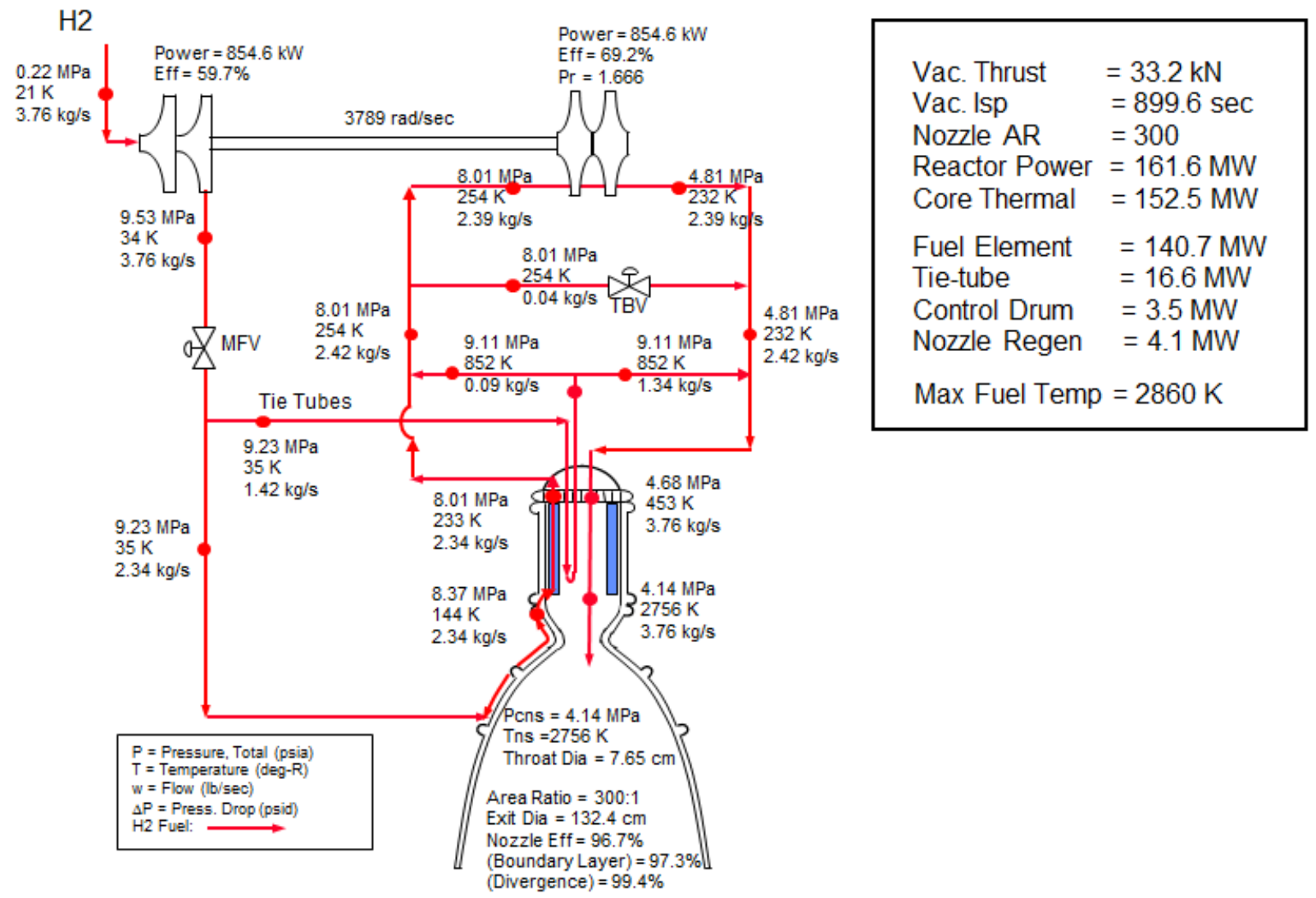

Figure 5. Small NERVA System Results

A comparison summary of the reactor is shown in Table 4. It should be noted that the component mass section is only an estimate. The reactor mass is estimated based on the results from the MCNP analysis. ${ }^{9}$ The pressure vessel, nozzle, and other numbers are based on scaling factors developed during the NERVA project. The scaling factors are used to estimate mass as a function of the thrust and the overall size of the reactor core.

\section{Discussion}

There were several difficulties in the design of this engine. The biggest issue to resolve was the temperature of the hydrogen entering the turbine. Since the RL-10 operates on an expander cycle, the temperatures experienced by the turbomachinery are quite low. However, the total energy available from the small NERVA engine design is much greater than necessary. This is due to the large fraction of tie tubes in the engine that are necessary to maintain criticality at such a low thrust level. In order to compensate for this, a small bleed from the tie tubes was used rather than the mixing the entire flow. However, this design feature introduces further risk since it complicates the flow path of the engine and also results in a very high tie tube outlet temperature. Further analysis is necessary to see if the tie tube elements can withstand the thermal stress from this high temperature environment.

As shown in Table 4, the engine achieved a thrust to weight ratio of 1.96 and a specific impulse of approximately 900 seconds. The specific impulse is primarily driven by the maximum allowable fuel temperature. In this analysis, the assumed maximum fuel temperature was $2860 \mathrm{~K}(5148 \mathrm{R})$. The thrust to weight of the engine is primarily related to the mass of the reactor core since this is the largest contributor. A lower thrust to weight is another complication from the low thrust level. A low thrust level requires more tie tubes and larger radial reflectors. This significantly reduces the thrust to weight of this engine. More work will need 
to be performed to identify if the reactor mass can be reduced by returning to a $2: 1$ fuel element to tie tube ratio from the current 1:1 ratio with some other approach to enhance criticality.

\section{Large NERVA Derived Engine}

\section{A. Engine Configuration}

The large engine is designed to produce enough thermal power to generate approximately $112.1 \mathrm{kN}$ of thrust. Since this engine is much larger than the $33.4 \mathrm{kN}$ NERVA derived engine, fewer tie tubes are needed to provide adequate criticality. For this engine, the fuel element to tie tube ratio was changed to approximately 2:1 which is the ratio studied for the small nuclear rocket engine (SNRE). Figure 6 shows a detailed view of the general pattern concept. ${ }^{9}$ In total, the engine has 564 fuel elements and 241 tie tube elements with a total thermal power of $555 \mathrm{MW}$. The reactor core is surrounded by $14.7 \mathrm{~cm}$ thick radial reflector and control drums. The core is estimated to have a total mass of $2645 \mathrm{~kg}$, containing $36.8 \mathrm{~kg}$ of ${ }^{235} \mathrm{U}$.

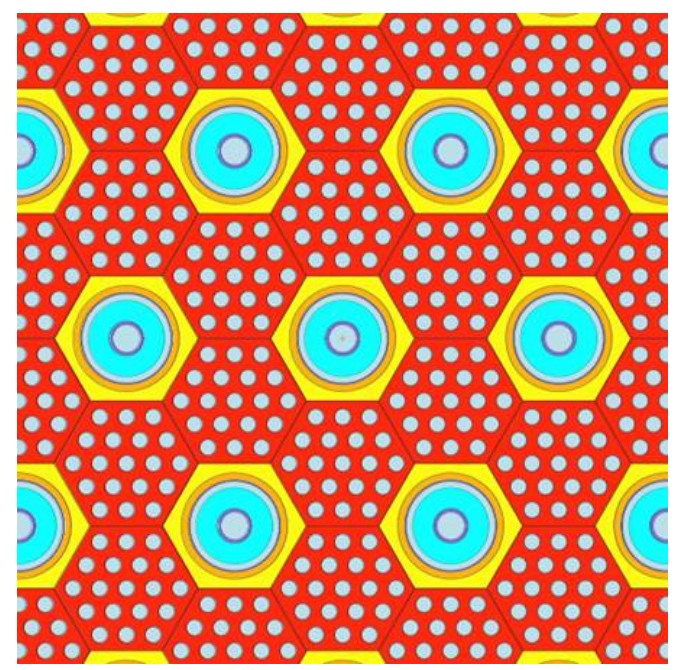

Figure 6. SNRE (2:1) Fuel Element and Tie Tube Configuration

The fuel element to tie tube pattern shown in Figure 6 is repeated throughout the reactor. Near the edge of the core, there are beryllium filler elements that are used to increase criticality and to make to the core circular. The power distribution in this reactor is given in Table 3 .

Table 3. Large NERVA Derived Engine Summary

\begin{tabular}{lrc} 
Description & Value & Units \\
\hline Number of Fuel Elements & 564 & NA \\
Number of Tie Tubes & 241 & NA \\
Avg. Power Deposited Fuel Element & 0.9386027 & MW \\
Reactor Total Power & 555 & MW \\
Fuel Element Hydrogen Heating & 529.3 & MW \\
Tie Tube Hydrogen Heating & 39.1 & MW \\
Conduction from Fuel Elements & 27.1 & MW \\
Nuclear Deposited & 12.0 & MW \\
Control Drum Hydrogen Heating & 10.9 & MW
\end{tabular}

\section{B. Engine Flow Path}

As with the small NERVA engine, there is plenty of thermal energy available to power the turbomachinery. The main difference between the small engine and the large engine is that the engine is operated with dual 
turbopumps in parallel. Since the ratio of tie tubes to fuel elements is lower for this reactor, there is less need to bypass some of the tie tube exit flow. The flow path is illustrated in in the results section in Figure 7.

\section{Model Results}

The model was run to obtain a chamber pressure of $6.89 \mathrm{MPa}$ (1000 psia) and a peak fuel temperature of $2860 \mathrm{~K}$ (5148 R). This specific state was chosen due to turbomachinery pump discharge pressure limitations and fuel element temperature limitations. It should be noted that the pressure drop through the regenerative cooling sections are estimated using resistance values that scale the pressure drop with the mass flow rate of the engine.

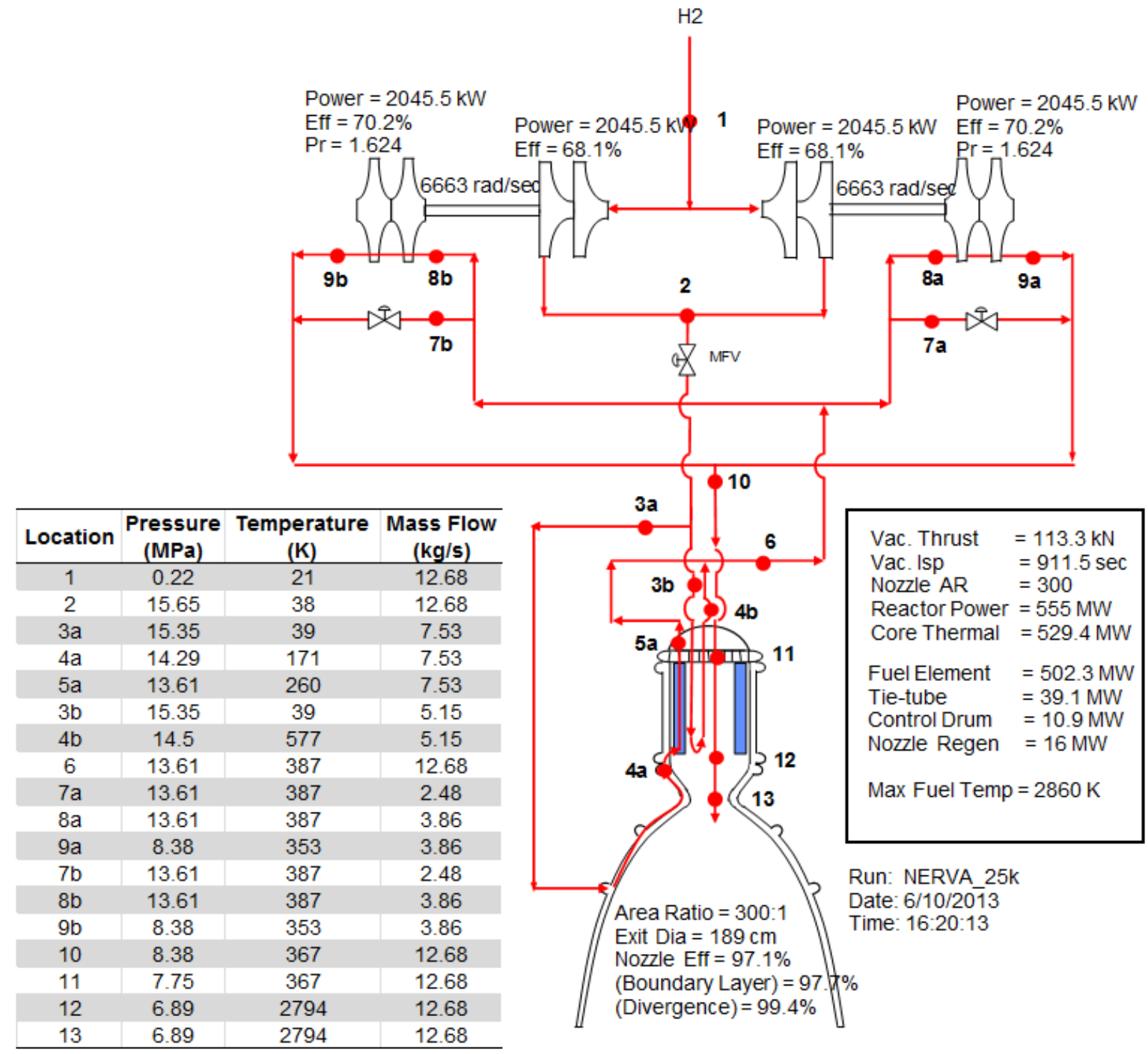

Figure 7. Large NERVA System Results

A comparison summary of the reactor is shown in Table 4. It should be noted that the component mass section is only an estimate. The reactor mass is estimated based on the results from the MCNP analysis. ${ }^{9}$ The pressure vessel, nozzle, and other numbers are based on scaling factors developed during the NERVA project. The scaling factors are used to estimate mass as a function of the thrust and the overall size of the reactor core. 


\section{Discussion}

One major concern for the NERVA derived engines is that the turbine inlet temperatures may exceed the nominal temperatures experienced in an expander cycle. As with the small NERVA derived engine, the large engine transfers a significant amount of energy to the hydrogen in the tie tubes. As discussed before, this is not considered as much of an issue for the large engine since the fuel element to tie tube ratio is greater which lowers the turbine inlet temperature.

Another interesting result is that the specific impulse of the large engine is greater than the small engine by approximately 12 seconds. Both the small and large NERVA derived engines were analyzed with an assumed peak fuel temperature of $2860 \mathrm{~K}(5148 \mathrm{R})$. The higher specific impulse of the large engine is attributed to the longer fuel elements which have a greater heat transfer area. This larger area results in a lower thermal gradient between the fuel element and hydrogen coolant. The large engine also has much greater performance than the small engine in terms of thrust to weight. This is mostly attributed to the larger fuel element to tie tube ratio which resulted in a approximately half the number of reactor elements per unit thrust.

\section{Small ANL-200 Engine}

\section{A. Engine Configuration}

The small CERMET engine is based on the ANL-200 fuel element design. The engine core contains a total of 121 fuel elements for a total reactor thermal power of $160 \mathrm{MW} .^{9}$ Since this is a fast spectrum reactor, no neutron moderation is required and the core is only composed of fuel elements. The reactor core is surrounded by a $10 \mathrm{~cm}$ thick $\mathrm{BeO}$ radial reflector as well as control drums to improve criticality. In order to reduce neutron leakage, there is a $15.24 \mathrm{~cm}$ axial reflector at the inlet of the reactor core. The reactor core is estimated to have a mass of $1000 \mathrm{~kg}$ and contains $177.3 \mathrm{~kg}$ of ${ }^{235} \mathrm{U}$.

\section{B. System Results}

The small CERMET engine utilizes a flow path that is nearly identical to the flow path for the small NERVA derived engine. The only difference is that the CERMET engine does not have a parallel flow for tie tubes since there are no tie tubes in the system. The simulation set point was a chamber pressure of $3.79 \mathrm{MPa}$ (550 psia) and a maximum fuel temperature of $2860 \mathrm{~K}(5148 \mathrm{R})$. In this system, the chamber pressure is limited due to the available energy to run the turbomachinery. 


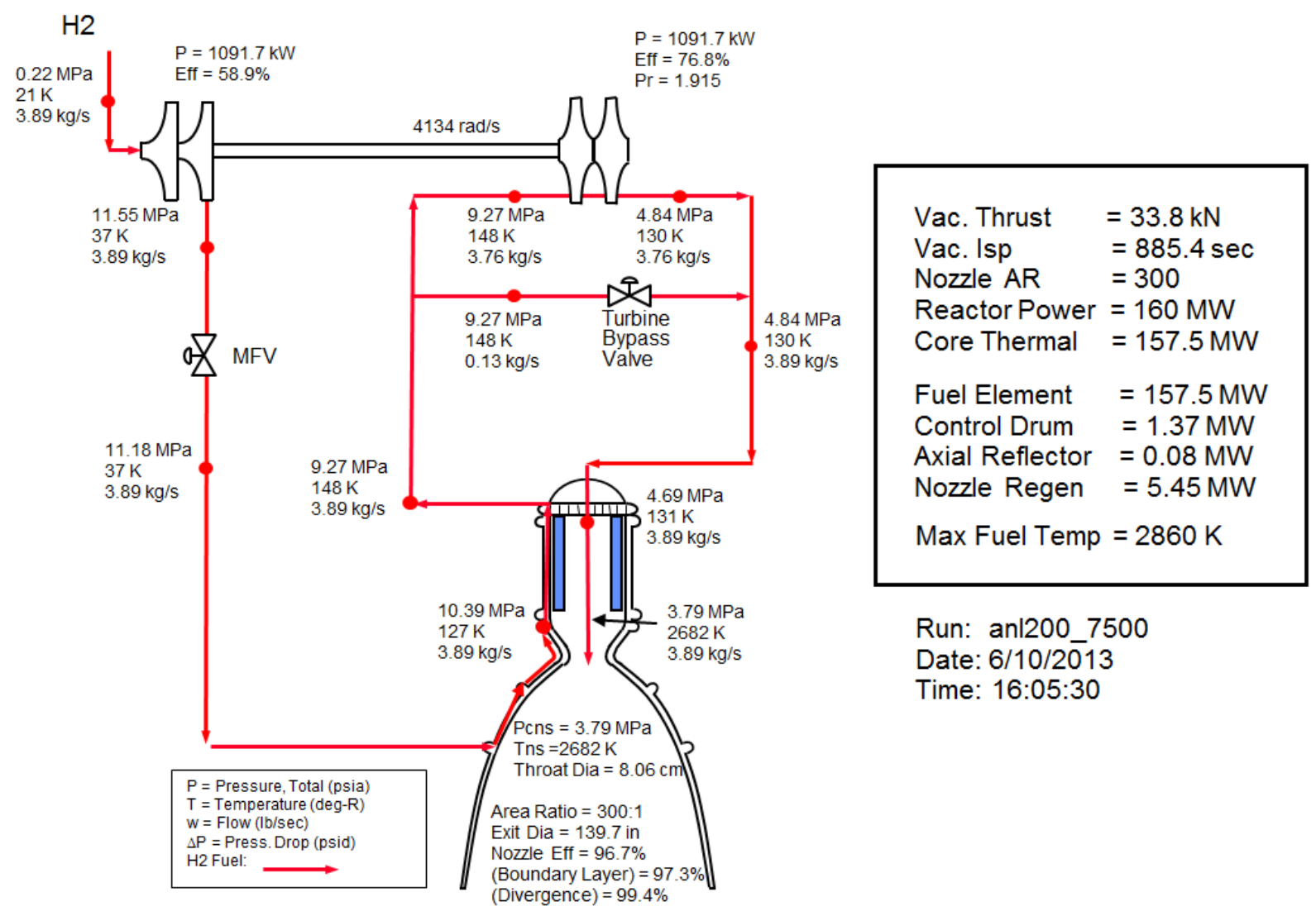

Figure 8. Small ANL-200 Engine System Results

A comparison summary of the reactor is shown in Table 4. It should be noted that the component mass section is only an estimate. The reactor mass is estimated based on the results from the MCNP analysis. ${ }^{9}$ The pressure vessel, nozzle, and other numbers are based on scaling factors developed during the NERVA project. The scaling factors are used to estimate mass as a function of the thrust and the overall size of the reactor core.

\section{Discussion}

The small ANL-200 CERMET engine achieves a thrust of $33.8 \mathrm{kN}\left(7591 \mathrm{lb}_{\mathrm{f}}\right.$ ) and a specific impulse of 885.4 seconds. The specific impulse is lower than the comparable small NERVA derived engine primarily because the chamber temperature is lower for the CERMET engine for the same peak fuel temperature. This is likely because the fuel element is thirty percent shorter than the NERVA fuel element which results in a higher thermal gradient between the fuel element and the hydrogen gas. The major concern for the CERMET engine is the available thermal energy to run the turbomachinery. In this analysis, the maximum chamber pressure attainable is near the operation point, $3.79 \mathrm{MPa}(550 \mathrm{psia})$. This occurs primarily because the CERMET engine does not have regeneratively cooled tie tubes to increase propellant temperature. The CERMET engine also has approximately one third of the energy deposition in the reflector and control drums as compared to the NERVA derived engine. The amount of available energy is an issue when attempting to scale this design to a higher thrust level.

The small CERMET engine achieves a higher thrust to weight ratio than the small NERVA engine. This is primarily because the CERMET engine is more compact since it does not require tie tubes. The majority of the mass in any system is the reactor core. Although CERMET fuel is more dense, the smaller volume core is lighter and requires a lighter structure, radial reflector, and pressure vessel. All of these factors contribute to making the reactor substantially lighter than the comparable NERVA engine. 


\section{Large ANL-200 Engine}

\section{A. Engine Configuration}

The large CERMET engine is also based on the ANL-200 fuel element design. The reactor design analyzed is regarded as the radial growth option since the additional power compared to the small engine is obtained primarily by adding fuel elements. However, the fuel element length was also extended to $86.36 \mathrm{~cm}$ (34 inches). The engine core consists of 241 fuel elements for a total reactor power of $513 \mathrm{MW}$. The reactor core is surrounded by a $10 \mathrm{~cm}$ thick radial reflector as well as control drums to improve criticality. In order to reduce neutron leakage, there is a $15.24 \mathrm{~cm}$ axial reflector at the inlet of the reactor core. The reactor core is estimated to have a mass of $2356 \mathrm{~kg}$ and contain $376.7 \mathrm{~kg}$ of ${ }^{235} \mathrm{U}$.

\section{B. System Results}

The overall engine system for the large ANL-200 reactor is based around a hot bleed cycle rather than the typical expander cycle. This is due to a combination of factors. First, lack of sufficient thermal energy for the turbomachinery in the CERMET systems results in a limit to the maximum thrust obtainable. Secondly, the reactor design for the large ANL-200 engine is an exasperating condition. In order to maintain a relatively compact engine core diameter, the fuel element had to be extended to $86.36 \mathrm{~cm}$ from 60.96 $\mathrm{cm}$ which correspondingly increased the power per fuel element. The combination of increased length and increased power per fuel element greatly increased the pressure drop across the reactor and therefore required a higher pump discharge pressure.

In order to obtain the necessary energy to drive the turbomachinery, a hot bleed cycle had to be used. However, the hot bleed cycle reduces the average specific impulse of the system by as much as 65 seconds as illustrated in Figure 9. The hot bleed cycle is implemented by mixing a portion of the flow exiting the control drum/reflector cooling loop with a bleed from the outlet of the reactor core. The ratio of cool to hot flow was proportioned in order to obtain a turbine inlet temperature of $833 \mathrm{~K}(1500 \mathrm{R})$. The turbine exhaust is directed through a 2:1 area ratio nozzle in order to recuperate some of the losses from a hot bleed cycle. The remaining flow from the control drum/reflector outlet is directly fed into the reactor core. The results are shown in Figure 9 and Table 4. 


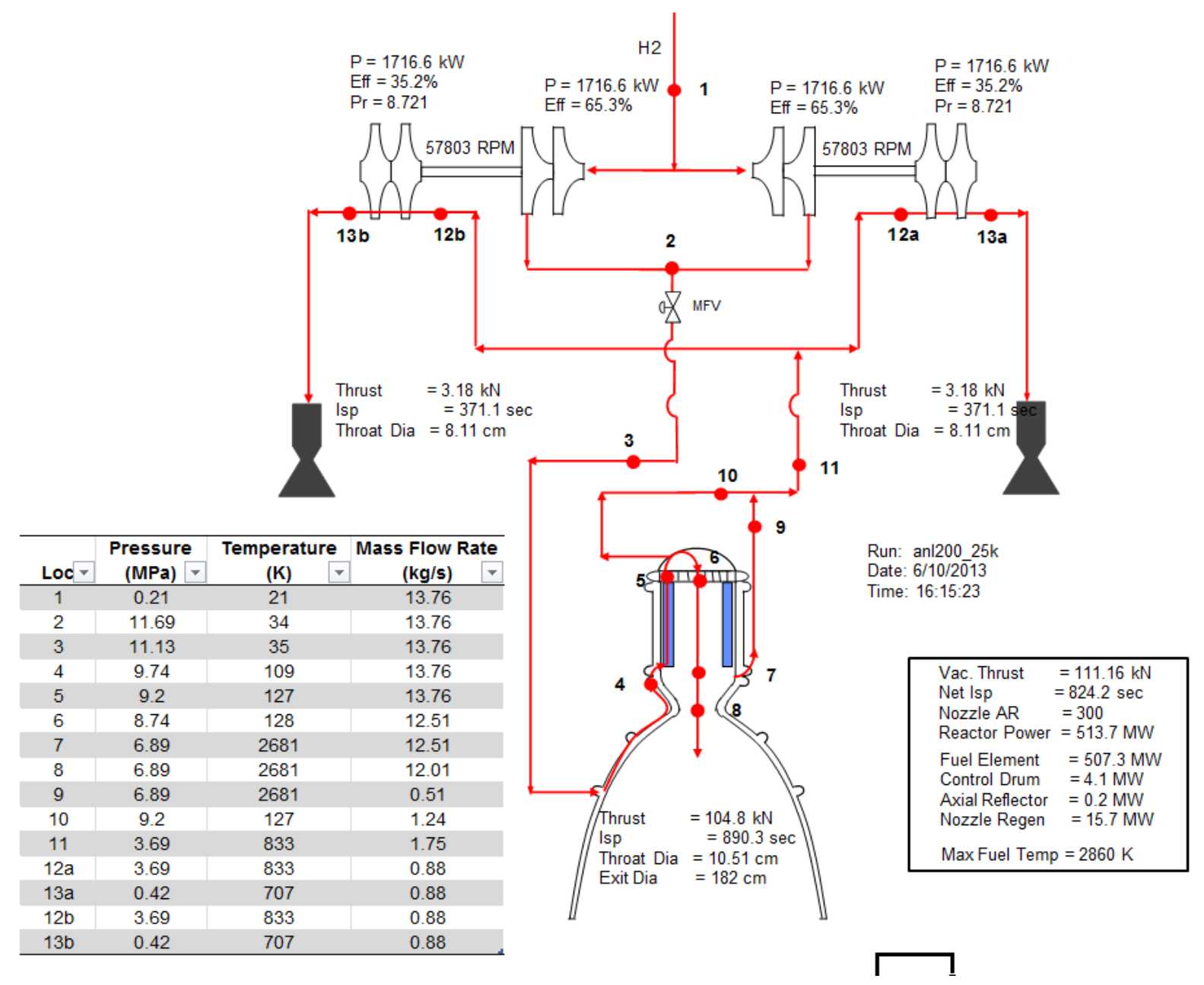

Figure 9. Large ANL-200 Hot Bleed Cycle Results

A comparison summary of the reactor is shown in Table 4. It should be noted that the component mass section is only an estimate. The reactor mass is estimated based on the results from the MCNP analysis. ${ }^{9}$ The pressure vessel, nozzle, and other numbers are based on scaling factors developed during the NERVA project. The scaling factors are used to estimate mass as a function of the thrust and the overall size of the reactor core.

\section{Discussion}

The major issue with the large CERMET engine using the ANL-200 fuel element geometry is the pressure drop across the reactor and the lack of available thermal energy for the turbomachinery. For this analysis, a hot bleed cycle was analyzed. There are other potential options for providing the necessary energy, such as using some outer elements as heater elements in parallel with the nozzle cooling. ${ }^{12}$ Since a hot bleed cycle was examined, it is also assumed that the RL-60 turbomachinery will not be suitable. Therefore this design may involve added development costs relative to other designs examined.

\section{Discussion}

Each engine design has its own strengths and weaknesses as can be seen in Table 4. For the small engine design, the CERMET engine has better thrust to weight and a higher specific impulse. The higher thrust to weight is due to the smaller, more compact engine design. Also, the small CERMET engine has a much 
simpler flow path design than the NERVA derived engine since it does not have tie tubes. However, the small CERMET engine requires over six times the amount of highly enriched ${ }^{235} \mathrm{U}$. If the cost or availability of enriched uranium is a major contributor to the engine, this may preclude the use of a CERMET engine.

When the desired thrust is increased to $112.1 \mathrm{kN}\left(25 \mathrm{klb}_{\mathrm{f}}\right)$, the benefits of CERMET seen in the small engine start to decrease. This is primarily driven by the high pressure drop across the high thrust CERMET core and the limited available energy for the turbopump operation. In order to get the engine cycle balance to close, a hot bleed cycle was adopted which lowered the overall specific impulse of the engine and increased the complexity of the design. Not only is the performance of the engine worse than the large NERVA engine, it also requires approximately ten times the amount of enriched uranium. However, a lower pressure drop and a reduction of enriched uranium might be achieved by redesigning the fuel element and reactor core.

Table 4. Engine Comparison

\begin{tabular}{|c|c|c|c|c|c|}
\hline Description & $\begin{array}{l}\text { Small } \\
\text { NERVA }\end{array}$ & $\begin{array}{l}\text { Small } \\
\text { CERMET }\end{array}$ & $\begin{array}{l}\text { Large } \\
\text { NERVA }\end{array}$ & $\begin{array}{l}\text { Large } \\
\text { CERMET }\end{array}$ & Units \\
\hline \multicolumn{6}{|l|}{ Reactor } \\
\hline Active Fuel Length & 88.9 & 60.96 & 132 & 86.36 & $\mathrm{~cm}$ \\
\hline Radial Reflector Thickness & 14.7 & 10 & 14.7 & 10 & $\mathrm{~cm}$ \\
\hline Axial Reflector Thickness & - & 15.24 & - & 15.24 & $\mathrm{~cm}$ \\
\hline Engine Diameter & 87.7 & 55 & 98.5 & 68 & $\mathrm{~cm}$ \\
\hline Element Pattern Type & Dense & - & $2: 1$ & - & \\
\hline Number of Fuel Elements & 260 & 121 & 564 & 241 & \\
\hline Number of Tie Tube Elements & 251 & - & 241 & - & \\
\hline${ }^{235} \mathrm{U}$ mass & 27.5 & 177.3 & 36.8 & 376.7 & $\mathrm{~kg}$ \\
\hline \multicolumn{6}{|l|}{ Component Masses } \\
\hline Reactor & 1435 & 1215 & 2645 & 2722 & $\mathrm{~kg}$ \\
\hline Pressure Vessel & 110 & 50 & 280 & 150 & $\mathrm{~kg}$ \\
\hline Nozzle & 115 & 115 & 240 & 270 & $\mathrm{~kg}$ \\
\hline Turbomachinery-Piping & 40 & 40 & 90 & 135 & $\mathrm{~kg}$ \\
\hline Gimbal & 30 & 30 & 50 & 50 & $\mathrm{~kg}$ \\
\hline Engine Total & 1730 & 1450 & 3305 & 3327 & $\mathrm{~kg}$ \\
\hline \multicolumn{6}{|l|}{ Engine System } \\
\hline Thrust & 33.2 & 33.8 & 113.3 & 111.2 & $\mathrm{kN}$ \\
\hline Maximum Fuel Temperature & 2860 & 2860 & 2860 & 2860 & $\mathrm{~K}$ \\
\hline Chamber Inlet Temperature & 2756 & 2682 & 2794 & 2681 & $\mathrm{~K}$ \\
\hline Chamber Pressure & 4.14 & 3.79 & 6.89 & 6.89 & $\mathrm{MPa}$ \\
\hline Nozzle Expansion Ratio & 300 & 300 & 300 & 300 & \\
\hline Specific Impulse & 899.6 & 885.4 & 911.5 & 824.2 & sec \\
\hline Thrust to Weight & 1.96 & 2.38 & 3.49 & 3.41 & \\
\hline
\end{tabular}

\section{Conclusions}

Four nuclear thermal rocket (NTR) models have been created in the Numerical Propulsion System Simulation (NPSS) framework. Each engine was designed with the intent of potentially using existing turbomachinery. However, this was not attainable for the large CERMET engine based on the ANL-200 fuel element design. The other engine results compare closely to prior analysis performed by Fittje and Schnitzler using the Nuclear Engine System Simulation (NESS) tool. ${ }^{12,13}$ Potential issues for each engine design have been identified and future work will be directed to reduce these risks. 


\section{References}

${ }^{1}$ Borowski, S., McCurdy, D., and Packard, T., "7-Launch NTR Space Transportation System for NASA's Mars Design Reference Architecture (DRA) 5.0," AIAA-2009-5309, Aug. 2009.

${ }^{2}$ Houts, M., Borowski, S., George, J., Kim, T., Emrich, W., Hickman, R., Broadway, J., Gerrish, H., and Adams, R., "Affordable Development of a Nuclear Cryogenic Propulsion Stage," AIAA-2012-4308, 2012.

${ }^{3}$ Finseth, J., "Overview of Rover Engine Test: Final Report," NASA-CR-184270, Feb. 1991.

${ }^{4}$ Stauber, L., "Numerical Propulsion System Simulation (NPSS): An Award Winning Propulsion System Simulation Tool," NASA-TM-2002-211333, 2002.

${ }^{5}$ Clough, J., Integrated Propulsion and Power Modeling for Bimodal Nuclear Thermal Rockets, Ph.D. thesis, University of Maryland, College Park, 2007.

${ }^{6}$ Clough, J., Starkey, R., Lewis, M., and Lavelle, T., "Reactor Modeling for Bimodal Nuclear Thermal Rockets," AIAA2006-4556, 2006.

${ }^{7}$ Technology, A. S., "RL-10 Specifications," http://www.spaceandtech.com/spacedata/engines/rl10_specs.shtml.

${ }^{8}$ Durham, F., "Nuclear Engine Definition Study Volumes I-III," LA-5044-MS, 1972.

${ }^{9}$ Schnitzler, B., "Small Reactor Designs Suitable for Direct Nuclear Thermal Propulsion: Interim Report," INL-EXT-1224776, Feb. 2012.

${ }^{10}$ Fittje, J., "Upgrades to the Ness (Nuclear Engine System Simulation) Code," AIAA-2007-5620, 2007.

${ }^{11}$ Schnitzler, B. and Borowski, S., "Small Fast Spectrum Reactor Design Suitable for Direct Nuclear Thermal Propulsion," AIAA-2012-3958, 2012.

${ }^{12}$ Fittje, J. and Schnitzler, B., "Cycle Analysis of a 200 MW Class Cermet Based NTR Engine," AIAA-2012-3960, 2012.

${ }^{13}$ Schnitzler, B., Borowski, S., and Fittje, J., "Lower Thrust Engine Options Based on the Small Nuclear Rocket Engine Design," AIAA-2011-5846, 2011. 


